\title{
INFLUENCE OF "NICOFLOK" POLYMER- MINERAL WITH PORTLAND CEMENT ON GRANULAR SOILS AND RECYCLED ASPHALT MATERIAL
}

\author{
MAHDI ZIRAK BAROUGHI ${ }^{1}$, AMIR HASSAN REZAEI ${ }^{1 *}$, \\ HOOSHANG KATEBI ${ }^{2}$ \\ ${ }^{1}$ Department of Civil Engineering, Azarbaijan Shahid Madani University, \\ Tabriz, Iran \\ ${ }^{2}$ Department of Civil Engineering, Tabriz University, Tabriz, Iran
}

Received 23 October 2019; accepted 9 July 2020

\begin{abstract}
In road construction projects, due to the high volume of soil materials, the costs of supplying and transporting high-quality materials are very high, they may also include the crossing between different geotechnical lands with different types of soils and soil stabilization used to modify resistance characteristics of soil materials in different layers of the road. Addition of a stabilizing agent can improve the properties of aggregates and subgrade soils. In this study, the effect caused by the combined action of polymer-mineral composition "Nicoflok" and cement stabilization on the strength characteristics and durability of local materials, adopted from under-construction Ilkhchi highway project, was investigated. In addition, the effects of stabilizers on the recycled asphalt materials was studied to assess the possibility of using them in the pavement structure. Samples with 0, 0.5, 0.9 and 1.3 percent of Nicoflok
\end{abstract}

* Corresponding author. E-mail: rezaei.ah@azaruniv.ac.ir 
combined with varying percentages of cement content were made and CBR tests were conducted after curing. Strength degradation of samples under 50 cycles of freeze-thaw was also investigated. The results show that addition of cementNicoflok admixture to the subgrade soil considerably increases CBR values, which leads to reduction of the required material amount. The efficiency of this polymer with Portland cement depends on several factors, such as the amount of cement, curing time, size and shape of soil grains. The optimum dosage of Nicoflok was $0.9 \%$ mixed with $1 \%$ cement. Stabilizing the base and recycled asphalt materials with cement and Nicoflok also improves the long-term performance of the pavement.

Keywords: Stabilization, Nicoflok, Portland cement, CBR, recycled asphalt material, freeze-thaw cycles.

\section{Introduction}

Nowadays, such challenges as extension of transport infrastructures, increased number of vehicles together with increasing transportation load and intensity are countered by a considerable growth in the development of technologies increasing pavement-bearing capacity and improving pavement performance. Pavement performance is very responsive to the characteristics of road embankment materials. Also, poor subgrade soil conditions can result in inadequate pavement support and reduce pavement life. In some locations, the use of inappropriate land and soil materials is inevitable due to the linearity of road construction projects, road plan requirements and/or lack of good quality aggregates. One of the most effective solutions to this problem is the use of strengthened loose grounds, which cannot be used in pavement layer construction or as a subgrade if they are not strengthened and which are located in close proximity to the place of road construction.

Granular soils are commonly used as road embankment layers, which constitute a considerable part of road construction costs. The thickness of these pavement layers is very much dependent on the resistance of the material used and the quality of subgrade soils, over which they are going to be laid. Weaker materials essentially require thicker layers, whereas stronger ones go well with thinner pavement layers. Therefore, the increase in resistance of the subgrade and road structure materials leads to the decrease in the amount of required materials. This is especially important where high quality aggregates of high quality are not available. In order to improve the properties of the aggregates and subgrade soils, a wide variety of soil improvement methods are used (Han, 2015). In a comprehensive study conducted within the US Strategic Highway Research Study Program (SHRP), a total of 46 different ways of improving the soil quality were studied (Schaefer et al., 2009).
Influence

of "Nicoflok"

Polymer-Mineral

With Portland

Cement on Granular

Soils and Recycled

Asphalt Material 
Stabilization is modification of the physical and mechanical properties of the soil to achieve preset goals (Dejong et al., 2013). Stabilization in road construction is used to improve the mechanical properties of materials in order to turn the existing materials with inappropriate properties into materials suitable for different layers of road pavement and to improve the engineering performance of subgrades. Chemical stabilization of the soil is one of the most commonly used stabilization methods. Addition of a stabilizing agents can improve the properties of soils and aggregates. Chemical stabilizers are categorized as either traditional or nontraditional. Traditional additives include cement, lime, fly ash, and bituminous materials, whereas nontraditional additives include enzymes, liquid polymers, resins, acids, silicates, ions, and lignin derivatives. Nowadays, other additives, such as Cement Kiln Dust (CKD), Lime Kiln Dust (LKD), and Iron Furnace Slag Cement (GGBS) are also used (Kirsch \& Bell, 2013; Joe \& Button, 2003).

Numerous studies related to stabilization of road construction materials with fly ash, and fly ash in combination with other stabilizers have been conducted (e.g. Choudhary et al., 2017; Sahu et al., 2017; Kolias et al., 2005). Lime as one of the common and inexpensive stabilizers for stabilization of clayey subgrades (Mishra, 2012) and construction of forest roads (Pereira et al., 2018) has also been extensively studied. Cement has hydration abilities, as well as ability to cause pozzolanic reaction and cation exchange, which provide solid chemical bondings. Therefore, the geotechnical characteristics of soils will be improved in terms of plasticity, strength, stiffness, and durability (Petry \& Little, 2002). Cement-stabilized subgrades have been extensively used to improve the engineering performance of pavement structures (Wang et al., 2018). Nontraditional additives have been widely used in recent years. Use of Polypropylene Homopolymer (H030SG) improves the properties of clay in road embankments (Azzam, 2014). The effects of addition of a carboxylated styrenebutadiene emulsion (Tylac 4190) and Portland cement on the long-term performance of road base, crushed granite aggregates from the Kajang Rock Quarry in Malaysia, were studied by Shojaei Baghini et al. (2016).

A polymer-mineral composition Nicoflok, which is commonly used in combination with cement, is one of the additives that has been introduced and successfully used in recent years. However, in the course of literature review it has been discovered that only a few studies have been conducted on the effects of this polymeric material on cementstabilized soils, and thus supplementary studies seem necessary. Based on the studies conducted in Russia, using Nicoflok mineral polymer (NMP) with Portland cement could improve the ductility and strength of stabilized materials (Gusev \& Nekhoroshkov, 2013). 
Gusev \& Nekhoroshkov reported that the aggregates of three different roads in Russia were successfully stabilized with about $5 \%$ cement and $0.5 \%$ NMP. The compressive strength of the improved materials was about 6.5-7.7 MPa. The introduction of the polymer-mineral composition into the cement improves cement properties, such as beginning of setting and strength characteristics. The resulting composite cement belongs to a higher class of cement used in the strengthening the soil, which has a positive impact on the quality of the stabilized subgrade materials (Gridchin \& Zolotykh, 2018). Increasing the amount of Portland cement in materials stabilized by NMP with Portland cement increases the compressive strength and tensile strength of the samples made of desert sand and coastal sand. By increasing the amount of Portland cement and NMP, compressive strength of coastal sand under freeze-thaw cycles increases, but compressive strength of desert sands decreases (Rezaie Moghaddam et al., 2020). Gavrilina \& Bondar (2018) also performed uniaxial compressive strength test on road base materials, which contain Portland cement and 8-10 percent of NMP. They reported that Nicoflok additive increases the compressive strength and bending strength of the samples by $20 \%$. The conducted laboratory studies of soil stabilization with Nicoflok additive as the basis for asphalt-concrete and cement-concrete coats suggest that the use of Nicoflok polymer additive allows replacing stone materials in the road base with polymer-cementsoil (Gavrilina \& Bondar, 2018).

Resource saving is one of the most important issues pertaining to increasing economic efficiency. Natural resources are the main source of raw materials for road building materials, therefore, an integrated approach to their use is required. Significant results in resource saving in road construction can be achieved using recycled material. Recycled asphalt pavement (RAP) has increasingly been used as a base material for highway construction as a sustainable solution. Due to the existence of asphalt, $100 \%$ RAP typically has low strength and high potential of creep and permanent deformations (Thakur \& Han, 2015). Also, due to the chemical properties of bituminous aggregates, accumulation and maintaining asphalt materials, which have been extracted from the surface layer of old roads, are harmful to the environment. Therefore, considering the economic and environmental benefits of using RAP materials, it is important to find a new way to reuse these materials in different layers of the road. In order to ensure efficient reuse of recycled asphalt aggregates, their resistance properties should be improved, so establishing an appropriate method to stabilize these materials is important. As it has been already mentioned, a range of stabilizers has been used in stabilization of RAP, and many research projects on various properties of these materials have been implemented. Mechanical
Influence

of "Nicoflok"

Polymer-Mineral

With Portland

Cement on Granular

Soils and Recycled

Asphalt Material 
and volumetric properties of foamed bitumen mixtures containing different percentages of reclaimed asphalt pavement and bitumens were investigated by Kar et al. (2018). By comparing some of the physical properties of recycled asphalt aggregates and recycled concrete materials, it can be inferred that these materials are a suitable alternative to those commonly used in pavement layers. Their application may reduce construction costs and lead to reductions in greenhouse gas emissions (Edil, 2018). In this regard, Dołżycki, Jaczewski \& Szydłowski (2018) studied the impact of long-time chemical bonds on the stiffness modulus of mineral-cement-emulsion mixtures in the cold in-place recycling method.

NMP is one of the newest products for chemical stabilization, which can improve resistance specifications and durability of materials stabilized by Portland cement. There are few previous studies on the performance of NMP. In this study, the effect caused by the combined action of polymer-mineral composition "Nicoflok" and cement stabilization on the strength characteristics and durability of local materials, adopted from under-construction Ilkhchi highway project, was investigated. In addition, the effects of stabilizers on recycled asphalt materials were studied to assess the possibility of using them in the pavement structure. Due to the application of CBR results in the design of pavement layers, the CBR test was used in the present study. CBR test is one of the rapid and most common ways to evaluate the performance and strength of non-cohesive soils and aggregates stabilized with cement. Samples with 0, 0.5, 0.9 and 1.3 percent of Nicoflok combined with varying percentages of $0,0.5,1,1.5,2$ and 5 cement content were made and CBR tests were conducted after curing. In addition, the strength degradation of samples under 50 cycles of freeze-thaw was investigated. Thus, this study aims to improve the CBR values of in-situ loose subgrade soil as well as resistance and long-term performance of road embankment materials.

\section{Materials}

The physical and mechanical properties of all used materials are described in the the following sections 1.1.-1.2.

\subsection{Subgrade, subbase, base and Recycled Asphalt Pavement (RAP)}

Ilkhchi is located in the south east of Tabriz, the capital city of East Azerbaijan Province, Iran. As shown in Figure 1, the Ilkhchi highway project about $10 \mathrm{~km}$ in length is under construction. In 
this study, the stabilization of in-situ materials within this project, including 2 subgrade soils (Soil 1 and Soil 2), subbase layer materials (Soil 3), and base aggregate (Soil 4) using NMP with Portland cement was investigated. The subgrade soil samples were selected from two different points with different geotechnical characteristics. In some parts of the route, the subgrade soils were originally used for agricultural purposes and the top $100 \mathrm{~mm}$ of the soil was removed to clear the grass, roots and other organic materials. In addition, considering the economic and environmental benefits of using RAP, the effects of stabilizers on the recycled asphalt materials prepared
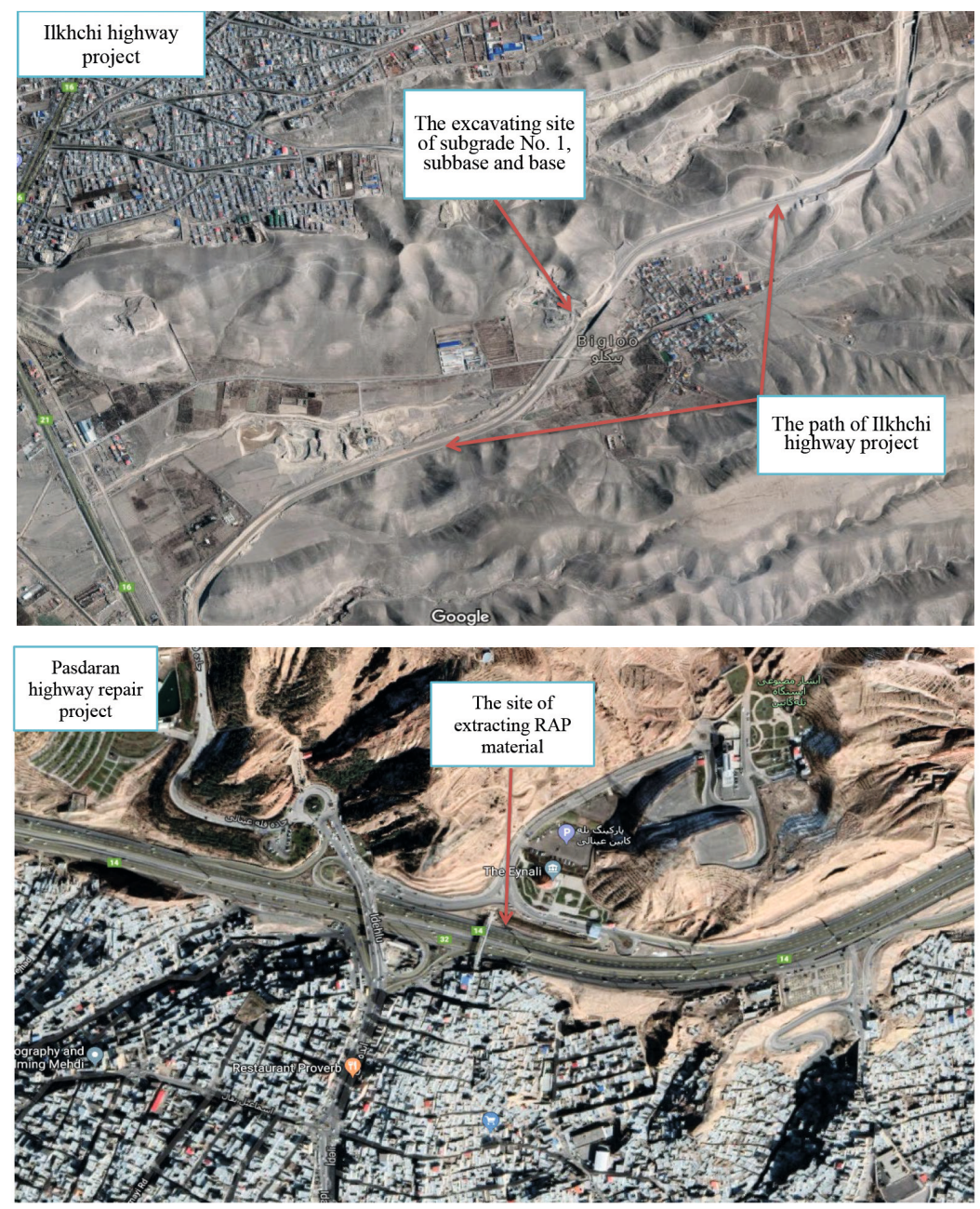

Figure 1. Locations of the Ilkhchi and Pasdaran highway projects
Mahdi Zirak Baroughi, Amir Hassan Rezaei, Hooshang Katebi

Influence

of "Nicoflok"

Polymer-Mineral

With Portland

Cement on Granular

Soils and Recycled

Asphalt Material 


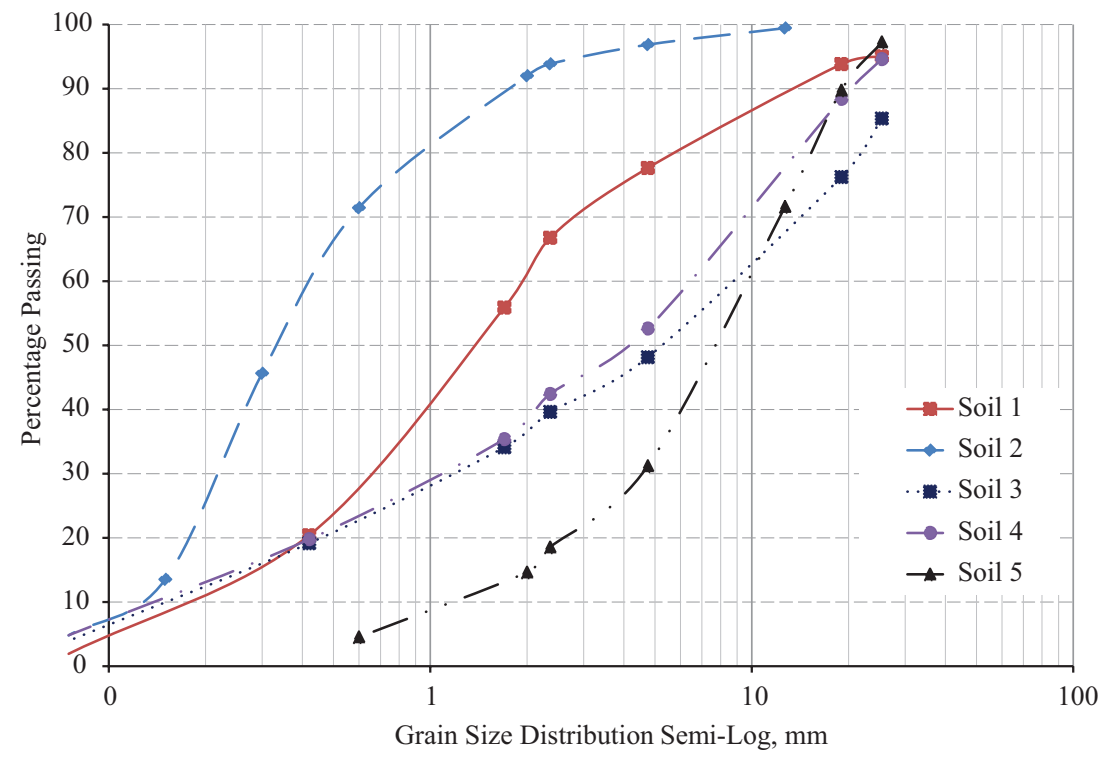

Figure 2. Materials grain size distribution curve (semi-log curve)

Table 1. Material Properties

\begin{tabular}{|c|c|c|c|c|c|c|c|c|c|}
\hline & $\begin{array}{c}\text { Material } \\
\text { type }\end{array}$ & $\begin{array}{c}\text { Soil } \\
\text { classification }\end{array}$ & $\begin{array}{c}\text { pp. 10, } \\
\%\end{array}$ & $\begin{array}{c}\text { pp. 200, } \\
\%\end{array}$ & $C_{c}$ & $C_{u}$ & CBR & SE & Project \\
\hline Soil 1 & subgrade & SP & 63 & 1.9 & 0.55 & 9.25 & 47.75 & 89.40 & $\begin{array}{l}\text { Ilkhchi } \\
\text { highway }\end{array}$ \\
\hline Soil 2 & subgrade & SP & 92 & 4.8 & 1.12 & 3.95 & 5.01 & 53.87 & $\begin{array}{l}\text { Ilkhchi } \\
\text { highway }\end{array}$ \\
\hline Soil 3 & subbase & GP & 37 & 3.6 & 0.8 & 52.5 & 35.66 & 65.31 & $\begin{array}{l}\text { Ilkhchi } \\
\text { highway }\end{array}$ \\
\hline Soil 4 & base & SW & 40 & 4.8 & 1.04 & 40.54 & 77.14 & 56.27 & $\begin{array}{l}\text { Ilkhchi } \\
\text { highway }\end{array}$ \\
\hline Soil 5 & RAP & GW & 15 & - & 1.45 & 7.44 & 10 & - & $\begin{array}{l}\text { Pasdaran } \\
\text { highway } \\
\text { repair } \\
\text { project }\end{array}$ \\
\hline
\end{tabular}

from the Pasdaran highway repair project in Tabriz (Soil 5) were studied to assess the possibility of using them in the pavement structure. Figure 1 shows the location of these projects. 


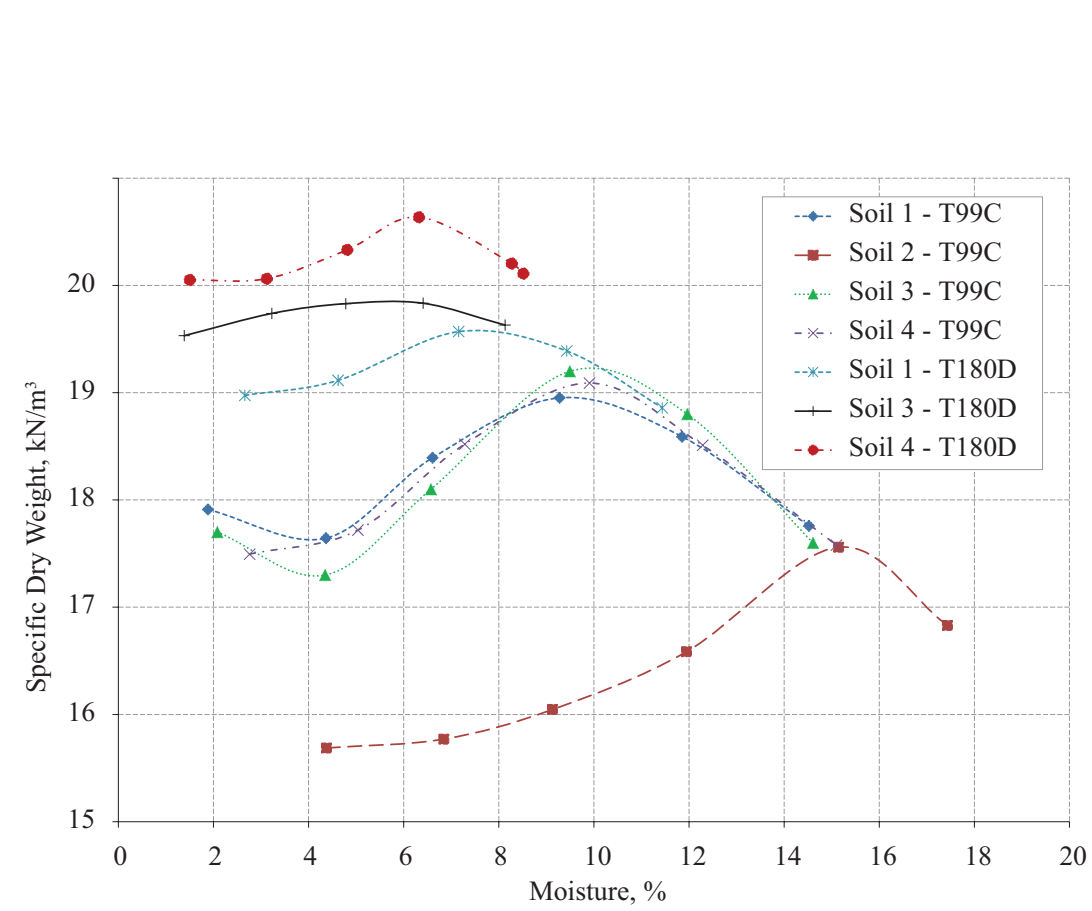

Mahdi Zirak Baroughi, Amir Hassan Rezaei, Hooshang Katebi

Influence

of "Nicoflok"

Polymer-Mineral

With Portland

Cement on Granular

Soils and Recycled

Asphalt Material

Figure 3. Material compaction curves

Table 2. Compaction Properties

\begin{tabular}{ccccc} 
& \multicolumn{2}{c}{ AASHTO T180D } & \multicolumn{2}{c}{ AASHTO T99C } \\
\cline { 2 - 5 } & $\gamma_{\text {dmax },} \mathrm{kN} / \mathbf{m}^{3}$ & $\boldsymbol{\omega}_{\text {opt, }} \%$ & $\gamma_{\text {dmax }} \mathbf{k N} / \mathbf{m}^{3}$ & $\omega_{\text {opt, }} \%$ \\
\hline Soil 1 & 19.58 & 7.5 & 18.96 & 9.4 \\
\hline Soil 2 & - & - & 17.57 & 15.25 \\
\hline Soil 3 & 19.85 & 5.8 & 19.25 & 9.8 \\
\hline Soil 4 & 20.64 & 6.2 & 19.1 & 9.9 \\
\hline
\end{tabular}

Firstly, the tests aimed at measurement of engineering parameters of soil layers were conducted on the prepared project samples. The grain size distribution curve of the tested material is shown in Figure 2. Soil classification based on the Unified Soil Classification System (USCS), coefficient of curvature $\left(C_{\mathrm{c}}\right)$ and uniformity coefficient $\left(C_{\mathrm{u}}\right)$ values are summarized in Table 1. CBR tests were conducted according to ASTM D1883-7 standard and the Sand Equivalent Value test (ASTM D2419) was performed to further identify the nature of the soils (Table 1). Also, Percentage of Fractured Particles test was done for aggregates of Soil 4 using ASTM D5821 method, which resulted in 91.29 percent of fractured coarse grains. 
Compaction tests according to AASHTO T180D and AASHTO T99C methods were carried out to identify the compaction properties of materials used in different pavement layers. The results of compaction tests are shown in Table 2 and Figure 3. Because of the hydrophobicity of asphaltic materials, the compaction test was not performed on them and the moisture content used in the experiments was fixed at $5 \%$ by weight of the basic RAP materials.

\subsection{Stabilizers: NMP Mineral Polymer (NMP) and Portland cement}

In the present study, the Portland cement type I-425 (M500) manufactured by Soufian Cement Company was used for stabilization. The density of the used cement was $3160 \mathrm{~kg} / \mathrm{m}^{3}$, and 3, 7 and 28 days compressive strength of the samples was equal to 260,386 and $520 \mathrm{~kg} / \mathrm{cm}^{2}$, respectively. NMP is a gray-colored powder that was presented by Nickel Co. in 2005, as shown in Figure 4. NMP has a density of 800 to $1200 \mathrm{~kg} / \mathrm{m}^{3}$ and moisture content of less than $2 \%$. More than $90 \%$ of these materials pass through sieve 0.315 . The XRF test according to ASTM E1621 was conducted on NMP. The obtained results are presented in Table 3. The chemical composition of the used Portland cement is shown in Table 3.

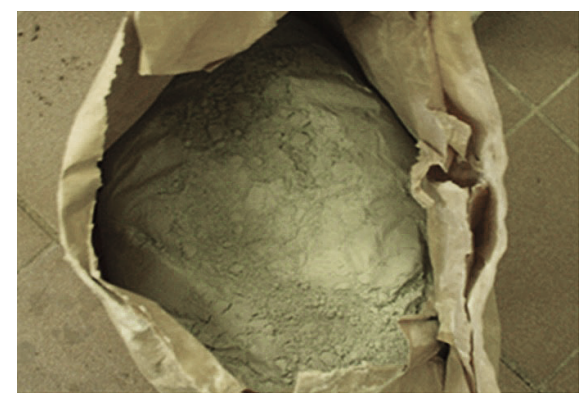

Figure 4. Nicoflok mineral polymer (NMP)

Table 3. Chemical composition of NMP and Portland cement

\begin{tabular}{lcccccccc}
\hline \multirow{2}{*}{ Materials } & $\mathbf{7}$ Composition percent, \% \\
\cline { 2 - 9 } & $\mathrm{CaO}$ & $\mathrm{SiO}_{2}$ & $\mathrm{Al}_{2} \mathrm{O}_{3}$ & $\mathrm{Fe}_{2} \mathrm{O}_{3}$ & $\mathbf{M g O}$ & $\mathbf{F}$ & $\mathbf{S O}_{3}$ & Other \\
\hline $\begin{array}{l}\text { Portland cement } \\
\text { type 1-425 }\end{array}$ & 63.25 & 21.24 & 4.70 & 3.64 & 2.38 & 1.13 & 2.06 & 1.6 \\
\hline NMP & 43.08 & 44.78 & 1.29 & 1.12 & 1.45 & 4.74 & - & 3.54 \\
\hline
\end{tabular}




\section{CBR tests results}

In this study, after grading and compacting tests with obtained moisture ratios, compacted samples stabilized with cement were made according to ASTMD558. All samples were compacted with the optimum moisture content obtained from the standard AASHTO T99-C test. Samples with 0, 0.5, 0.9 and 1.3 percent of Nicoflok combined with varying percentages of $0,0.5,1,1.5,2$ and 5 cement content were made and CBR tests were conducted according to ASTM D1883-7 standard after curing. The used material percentages are based on the weight of the raw materials (subgrade, subbase, base and RAP material). It should be noted that all experiments were performed twice and their mean values were reported, and the maximum observed difference between experiments with the same specification was about 3\%. In Figure 5, CBR test machine and a specimen after CBR test are shown. The results of these experiments will be presented in the following sections 2.1.-2.4.

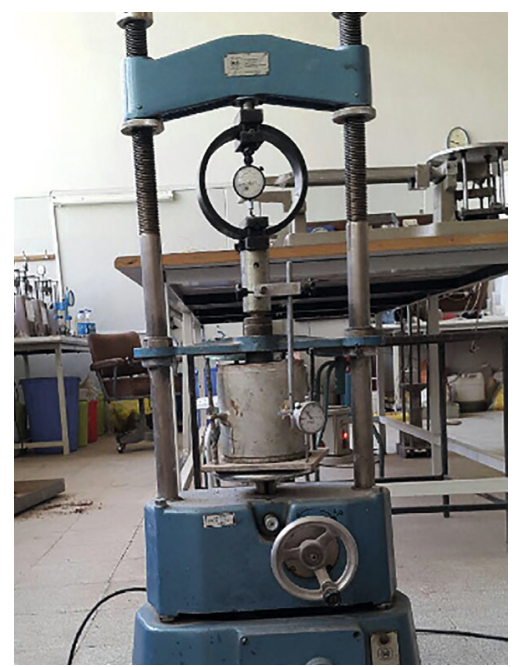

a)

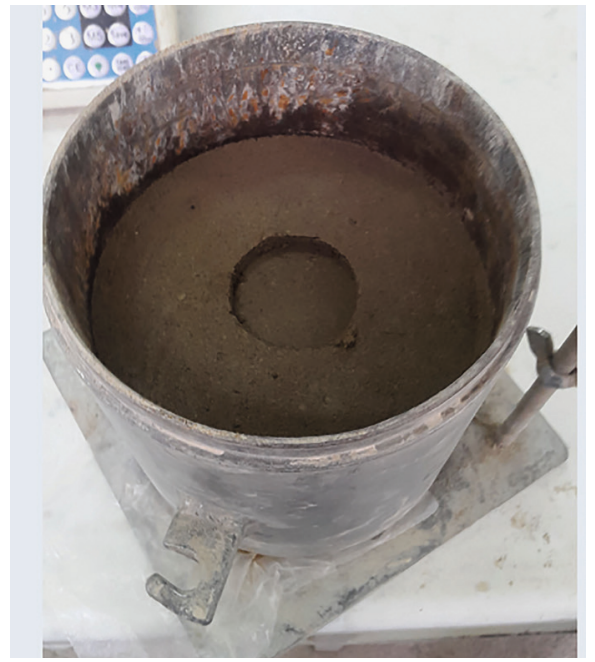

b)

Figure 5. A: CBR test machine, B: A specimen after CBR test

\subsection{Subgrade soils}

Figure 6 represents the CBR values of the stabilized subgrade soils with respect to NMP percentage for samples with 0.5 and 1 percent cement. As illustrated, for Soil 1 with $1 \%$ cement, after one day, the
Influence

of "Nicoflok"

Polymer-Mineral

With Portland

Cement on Granular

Soils and Recycled

Asphalt Material 
presence of NMP reduces the CBR values. But after three days of curing, the CBR of the samples began to increase slightly as NMP content increased. According to the Figure, adding NMP to Soil 2 stabilized samples has a positive effect on CBR. Also, when the percentage of Portland cement and the duration of curing is increased, the samples show higher CBR values. This is due to the starting of the hardening process of NMP and Portland cement. It seems that at the first stage of the hardening process, the amount of CBR in the samples stabilized with this polymer and Portland cement reduces. This is consistent with previous studies that the increase in the amount of non-applied fine particles in the samples and the nature of the NMP polymeric mineral content are considered possible reasons for the delay in the cementing process (Gusev \& Nekhoroshkov, 2013; Gridchin \& Zolotykh, 2018). According to Figure 2, most particles of Soil 2 have passed through sieve \#10 (2 mm) and it seems that in soils with finer grain distribution, Portland cement with NMP demonstrates better performance in stabilizing samples.

In order to study the effect of adding only cement, the CBR of Soil 2 stabilized samples with various cement percentages are presented in Figure 7. Regarding the test results of subgrade materials, the use of

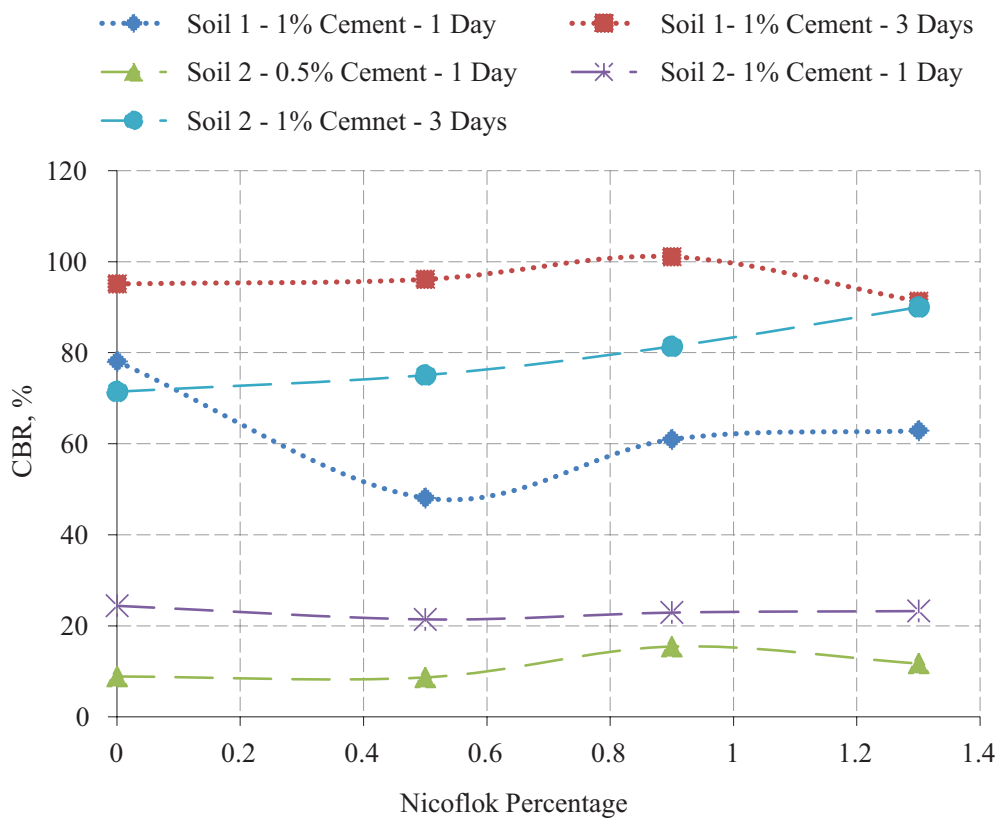

Figure 6. Effect of NMP on the subgrade material after 1 and 3 days of curing 


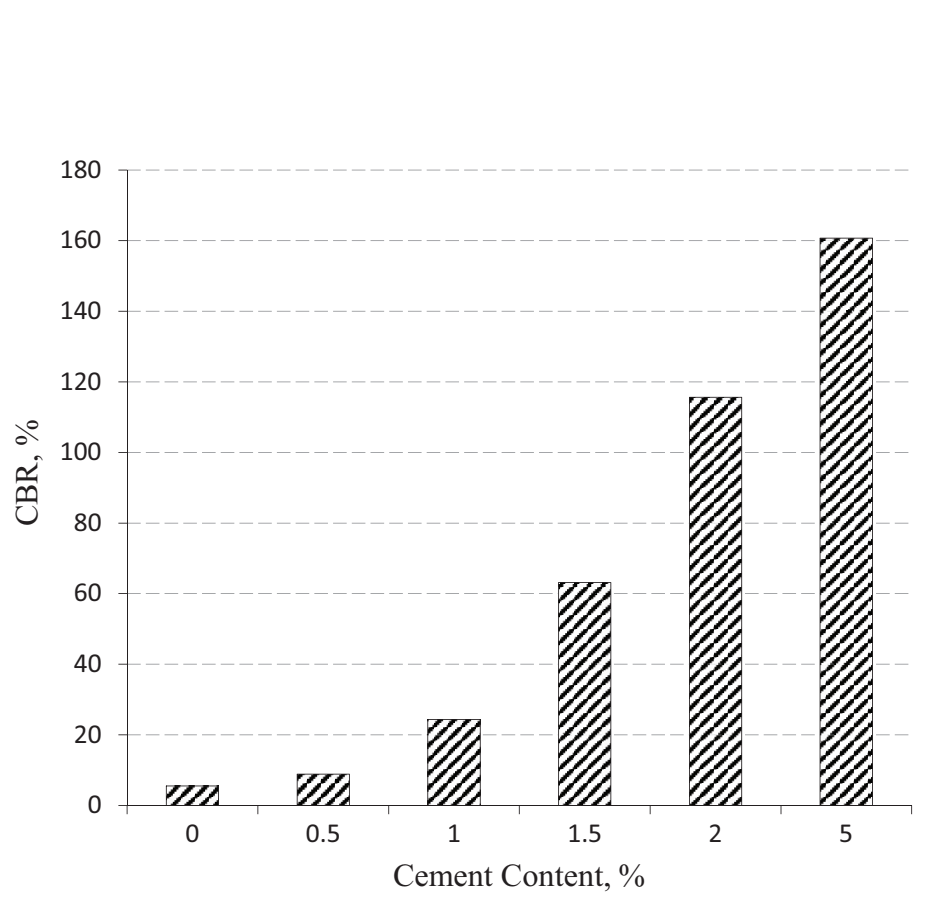

Figure 7. CBR variation in Soil 2 by increasing Portland cement content with 1 day of curing and without any NMP

cement only for stabilization caused significant CBR improvement in Soil 2 (which is the weaker one), so that CBR of the specimens with $0.5 \%$, $1 \%$ and $1.5 \%$ cement content increased from 5 (in specimens without cement and NMP) to 8, 24 and 63, respectively. As the cement content increases, the CBR values of the stabilized samples increase.

\subsection{Subbase material}

The effects of NMP percentage on the CBR values of the stabilized subbase material are shown in Figure 8. As shown, with the increase of NMP percentage, the CBR of the samples reduces. It seems that with the increase in the amount of NMP, as the amount of not activated mineral polymer increases due to the lack of reactive cement and low number of particles smaller than $2 \mathrm{~mm}$ (about 37\%, the smallest amount among the materials analysed in this study), we observe the inappropriate effect of NMP - sample load capacity decreases. This reductive effect for the samples with shorter curing times is more considerable. For the 3-day cured samples, the use of NMP with Portland cement reduces the CBR of the samples by $8.68 \%$ compared to the cement only stabilized sample.
Mahdi Zirak Baroughi, Amir Hassan Rezaei, Hooshang Katebi

Influence

of "Nicoflok"

Polymer-Mineral

With Portland

Cement on Granular

Soils and Recycled

Asphalt Material 


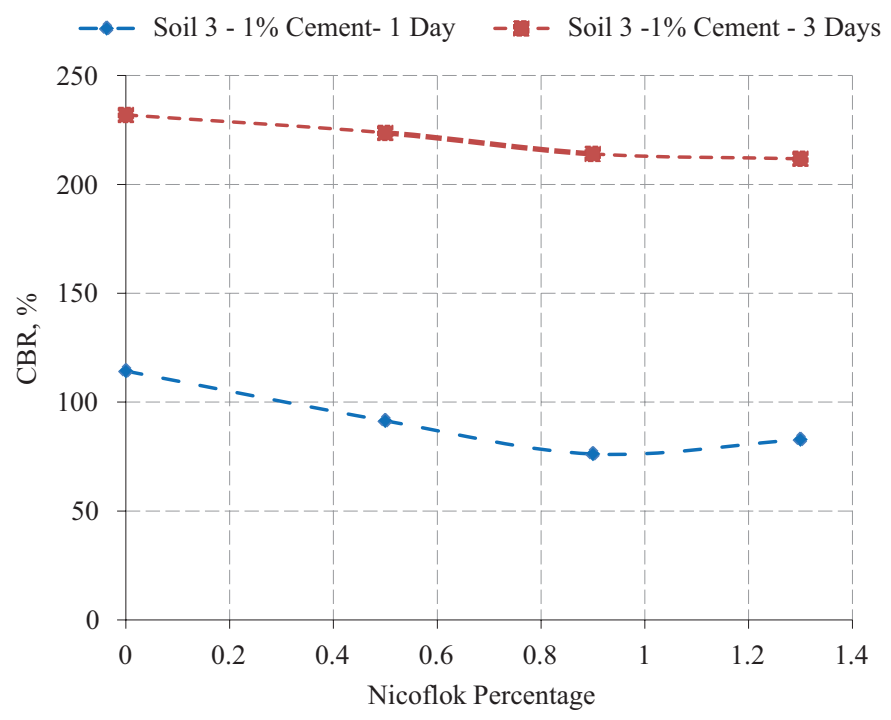

Figure 8. Effect of NMP on the subbase material after 1 and 3 days of curing

Also, given the fact that the subbase granules have rounded corners as compared to the base granules, and also because of the fact that in cement-stabilized mixtures, particles with sharper corners function better than those with the rounded corners, it can be inferred that soils which contain sharp corner granules will also demonstrate a better performance in the mixtures stabilized with NMP and Portland cement.

\subsection{Base material}

The results of the CBR tests on the base materials are illustrated in Figure 9. Considering the grain size distribution in Figure 2, the base material has more particles under $2 \mathrm{~mm}$ than subbase materials. It can be seen from Figure 9 that soil bearing capacity of the stabilized aggregate increased at $0.9 \%$ NMP $(5.74 \%$ relative to the samples without any NMP and containing Portland cement only) and then decreased. Firstly, this is due to the late start of the hardening process in the samples that were stabilized, and secondly, this is due to the nature of the polymer modifying the ductility properties of the samples stabilized by NMP and Portland cement. The base and the subbase materials have almost the same grain size, but demonstrate different behavior in the CBR under the influence of Portland cement and NMP. This is the reason why the base material has more granules with sharp edges than subbase materials and also more particles smaller than $2 \mathrm{~mm}$ (about 40\%). 
-Soil 4 - 1\% Cement- 3 Days

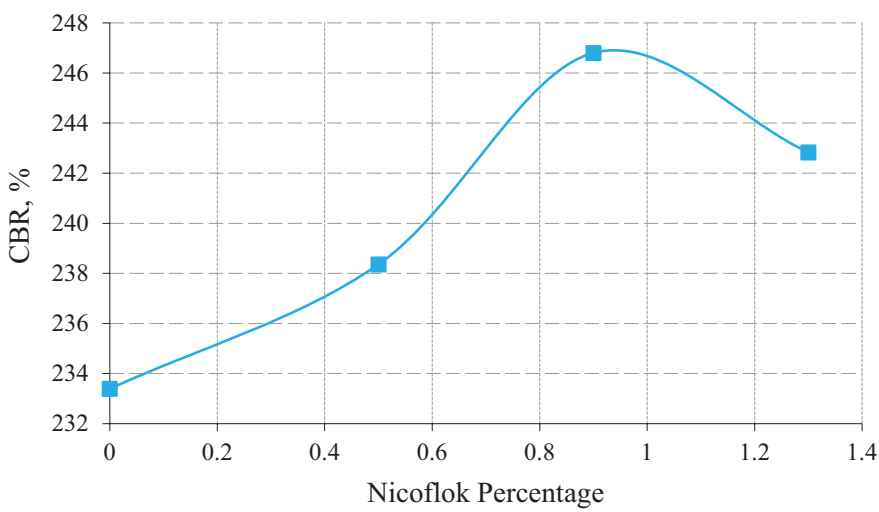

Figure 9. Effect of NMP on the base material after 3 days of curing

\subsection{RAP material}

In order to retain sustainability of the stabilized RAP material samples with regard of their bituminous nature, the amount of Portland cement in these samples inevitably increases to $3 \%$. These specimens are mixed with optimum value of $5 \%$ moisture content and compacted by AASHTO T99-C standard method. The results of

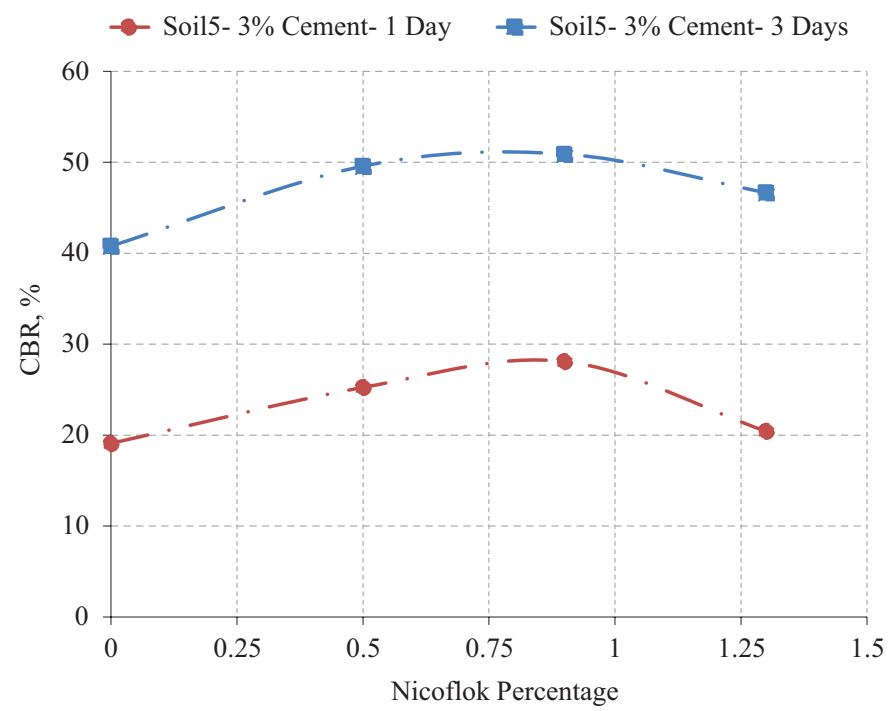

Figure 10. Effect of NMP on the RAP material after 1 and 3 days of curing of "Nicoflok"

Polymer-Mineral

With Portland

Cement on Granular

Soils and Recycled

Asphalt Material 
the CBR tests are shown in Figure 10 for recycled asphalt samples stabilized by NMP polymer and Portland cement. As shown, with the increase of NMP percentage up to $0.9 \%$, an increase in the load capacity of the stabilized RAP material is observed $(24.78 \%$ compared to the specimens without any NMP and containing Portland cement only). It seems that this observed trend may be explained by RAP materials gradation (about $85 \%$ of recycled asphalt particles have a size between $0.6 \mathrm{~mm}$ and $19 \mathrm{~mm}$ ), as well as a higher percentage of Portland cement in the recycled asphalt (3\%) compared to other materials used in this study. At constant cement content, when the amount of NMP increases to more than $0.9 \%$ and reaches $1.3 \%$, the CBR values reduce slightly. This probably is due to the increase in the amount of not reacted NMP particles that act as ineffective fine grains of the stabilized specimens.

\section{Durability tests results}

For testing the durability of RAP and base material samples stabilized by NMP and Portland cement, after three days of curing (ASTM C-192), CBR cylindrical specimens were removed from the molds. Samples after 3 day curing underwent 50 freeze-thaw (F-T) cycles according to ASTM-C666 standard. The temperature was varying between $4^{\circ} \mathrm{C}$ for thawing to $-18{ }^{\circ} \mathrm{C}$ for freezing. Each freeze-thaw cycle lasted about 5 hours and each complete F-T cycle test lasted 14 days (including curing days). In order to investigate strength degradation under 50 cycles of freeze-thaw, the samples were embedded in their specified mold and undergone the CBR test. In Figure 11, F-T cycles simulating equipment, as well as specimens before and after the tests are shown.

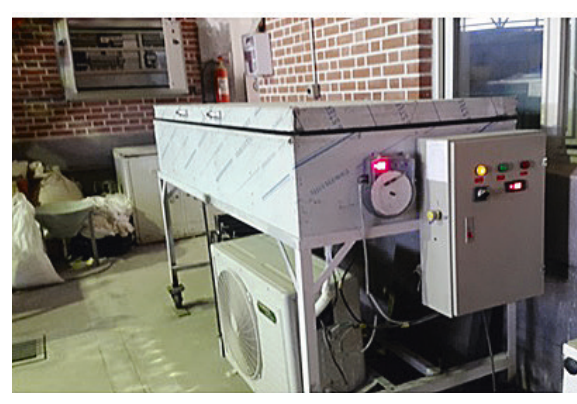

a)

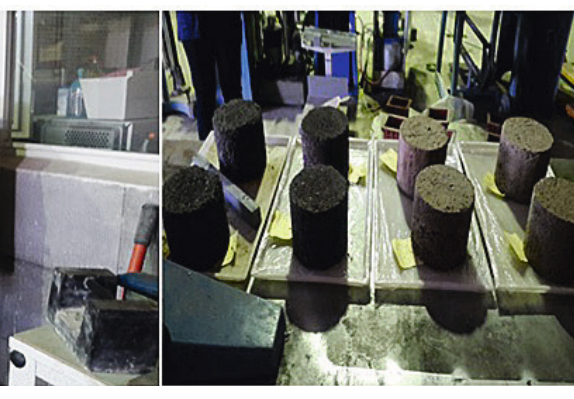

b)

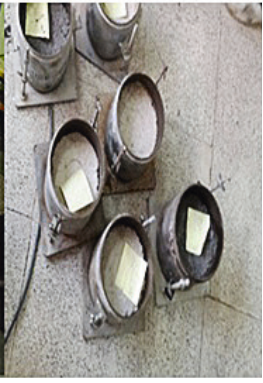

c)

Figure 11. A: F-T cycles simulating equipment, B: specimens after 50 F-T cycles (before CBR tests) and C: specimens after 50 F-T cycle process and CBR tests 
Figure 12 presents the effect of 50 F-T cycles on the CBR values of the of "Nicoflok" Polymer-Mineral stabilized base materials with 1\% cement and various NMP percentage. It can be seen that after F-T cycles, the CBR values of the samples with $0,0.5,0.9$ and 1.3 percent of NMP were reduced by $39.72 \%, 32.42 \%$, $27.03 \%$ and $57.39 \%$, respectively. Adding the stabilizer NMP up to $0.9 \%$ improves the durability of specimens and base materials stabilized by Portland cement and NMP. They demonstrate lower strength degradation under 50 freeze-thaw cycles, in comparison with base materials stabilized by cement only. This attests the proper functioning of the NMP polymer. However, higher amount of NMP affects ductility of the samples and increases the number of fine grains, which leads to increased CBR degradation under 50 freeze-thaw cycles. As a general rule, F-T cycles decrease CBR values of all stabilized base materials. The observed general trend concerning the effect of NMP content is similar to the CBR results of the stabilized material without F-T cycles.

The resulting CBR values of the stabilized RAP materials with $3 \%$ cement and NMP after 50 F-T cycles are illustrated in Figure 13. As it can be noticed, after F-T cycles, the CBR values of the samples with $0,0.5$ and 1.3 percent of NMP were reduced approximately by $14 \%, 18 \%$ and $2 \%$, respectively. For the stabilized samples with $0.9 \%$ NMP, the obtained CBR value after F-T cycles increased by about $15 \%$ compared to the samples after three days of curing and without subjecting to subsequent F-T cycles.

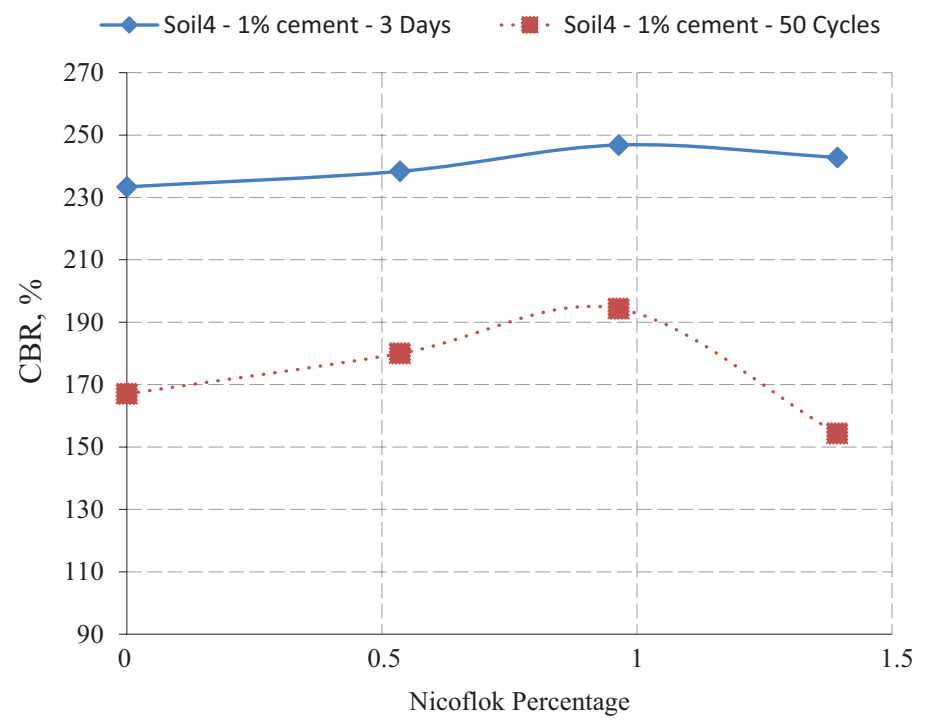

Figure 12. Stabilized base material CBR test results under successive F-T cycles

ith Portland

Cement on Granular

Soils and Recycled

Asphalt Material 


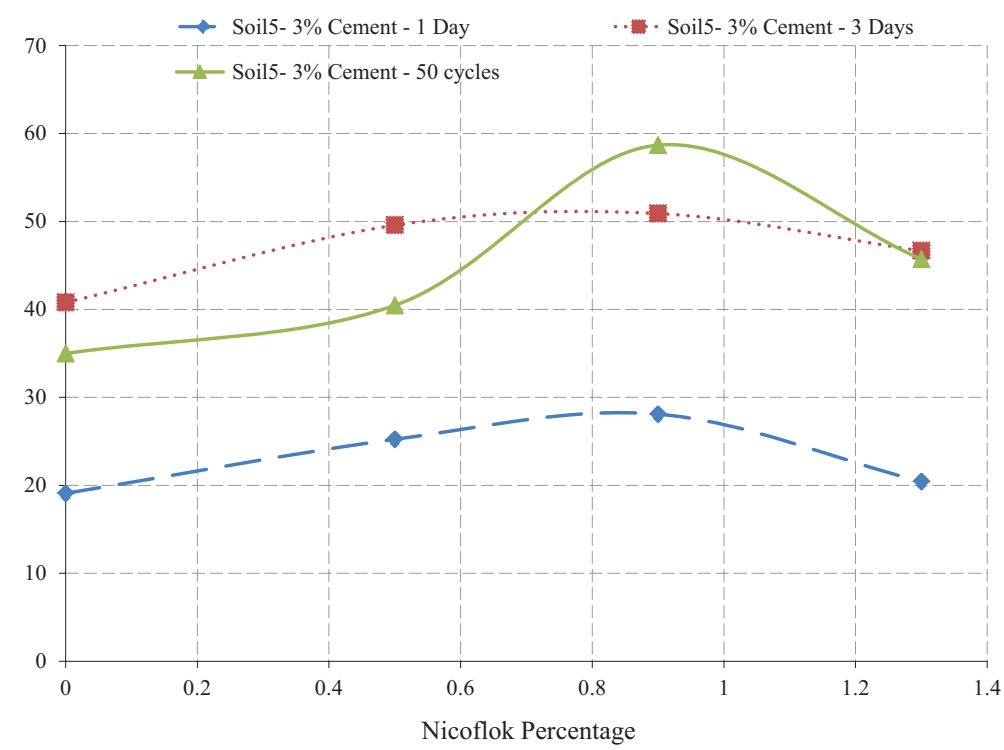

Figure 13. Stabilized RAP material CBR tests result under successive F-T cycles

It seems that due to higher percentage of cement in the stabilized RAP materials, NMP additive was more effective, even under 50 successive F-T cycles. Thanks to an increase of specimen age in days, the hardening process takes longer time, and CBR values show an increase. NMP improves the durability of the stabilized RAP materials so that adding $0.9 \%$ NMP to the stabilized samples with $3 \%$ cement leads to $67.7 \%$ of the increase in CBR compared to the samples containing Portland cement only. This implies that the specimens that were stabilized by appropriate content of NMP and Portland cement demonstrate better performance in terms of successive F-T cycles than the specimens, which were stabilized just by Portland cement. Also, in comparison with the stabilized base materials, the degradation of strength after F-C cycles was lower than in the stabilized RAP materials. Moreover, stabilization was more successful and effective in these materials.

In order to determine the percentage of volume loss and weight loss, the weight and volume of each sample were measured before and after 50 successive F-T cycles. As shown in Figure 14, as a general rule, with the increase of NMP content for both Soil 4 and Soil 5, weight loss increases in comparison with the samples without any NMP. This is likely because of the loss of water content as a result of NMP and Portland cement hardening process. The percentage 


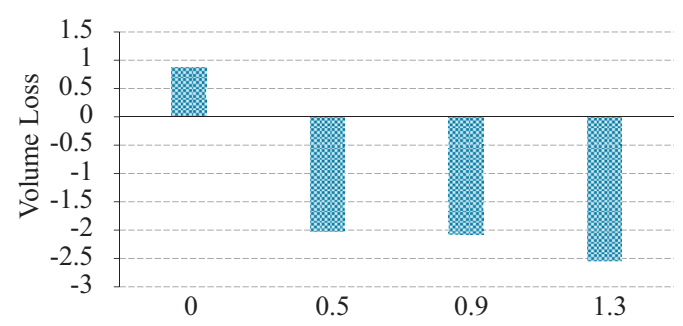

a)

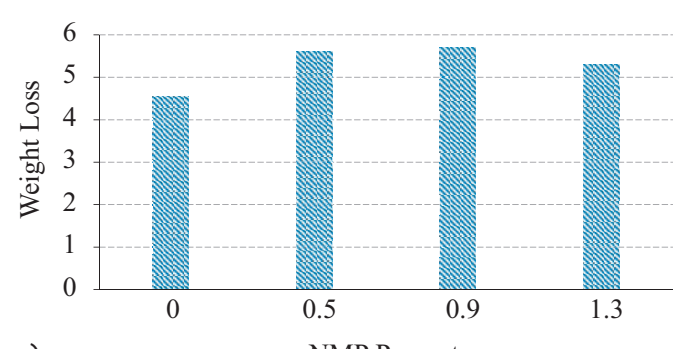

2020/15(5)

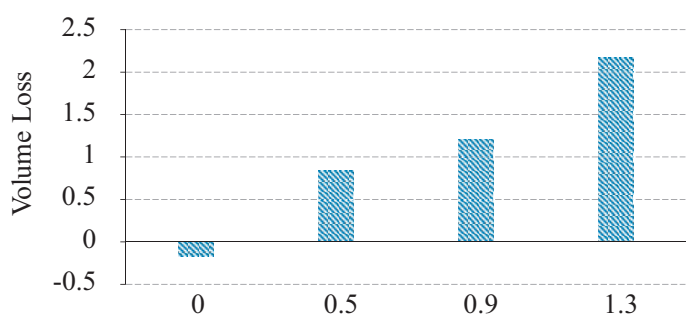

b)

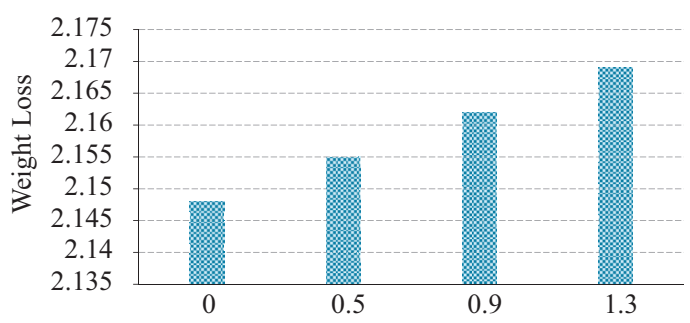

d)

NMP Percentage

Figure 14. Weight and volume loss results. Volume loss of the stabilized materials: A. Soil 4, B. Soil 5, and weight loss of the stabilized materials: C. Soil 4, D. Soil 5

of weight loss in the stabilized base material is more than the loss that occurred in the stabilized RAP material. It should be taken into consideration that the nature of this materials is different, Soil 5 has a bituminous nature and is characterized by better thermal insulation properties. Regarding the volume loss, due to different nature, Soil 4 and Soil 5 demonstrate a reverse performance in volume loss test. So it can be inferred that the use of NMP could have caused inflation in the stabilized base material and contraction in the stabilized RAP materials.

\section{Conclusion}

NMP is one of the newest products for chemical stabilization, which used together with Portland cement, can improve resistance specifications and durability of materials stabilized by Portland cement. In the present study, the effect caused by the combined action of polymermineral composition "Nicoflok" and cement stabilization on the strength characteristics and durability of local materials, adopted from underconstruction Ilkhchi highway project, were investigated. In addition, 
the effects of stabilizers on CBR and durability of the stabilized recycled asphalt materials was studied to assess the possibility of using them in the pavement structure. The main results of this study are as follows:

- Based on the obtained results, 0.9 percent of NMP is the optimal amount for the studied materials.

- Regarding the results of subgrade materials tests, using only cement for stabilization caused significant CBR improvement in Soil 2, which is the weaker one. The CBR of specimens with $0.5 \%$ and $1 \%$ cement content increased from 5 (in the specimens without cement and NMP) to 8 and 24, respectively. As a general trend, the NMP stabilizer improves the resistance properties of the studied subgrade soils. By adding 0.9\% NMP with one-day curing and low cement values (0.5\%), CBR increased by $74 \%$ in comparison with the specimens stabilized by cement only. In the specimens cured for 3 days with 1\% cement, the CBR value increased by about $14 \%$. In general, along with increasing curing time, the mixture of cement and NMP shows better performance.

- In subbase and base materials that were stabilized with only $1 \%$ cement, cement tripled CBR of specimens, but the addition of NMP to the stabilized subbase materials had a reductive effect, while the CBR values of the stabilized base materials slightly increased. This difference in performance can be due to the difference in the amount of finer grains (less than $2 \mathrm{~mm}$ ), as well as the sharp edges of the base material granules.

- In the case of RAP materials, the best NMP performance is related to $0.9 \%$ of NMP, which increased CBR up to $49 \%$ and $25 \%$ compared to the specimens stabilized with cement only, in 1 and 3 days curing, respectively. Stabilized RAP materials can be used as a road-building material that leads to resource-saving in road construction and economic and environmental benefits.

- In general, adding NMP up to $0.9 \%$ has made RAP and base materials more durable, so that the RAP and base materials with $0.9 \%$ NMP and cement after 50 successive F-T cycles have by $67 \%$ and $16 \%$ more CBR, respectively, than the samples stabilized with cement only. While samples stabilized with cement only have demonstrated a reduction in CBR after 50 cycles of F-T. Based on the results of this study and studies conducted by other researchers, NMP is more effective in combination with high percentages of cement content ( $3 \%$ and more).

- Finally, in terms of increasing CBR, adding NMP additive to the stabilized material with cement has a better impact on the performance of subgrade materials rather than on the subbase and base materials. 


\section{Acknowledgement}

We would like to express our gratitude to Poshesh Andodeh Mohafez (PAMCO) Company for providing NMP polymer. We also appreciate the staff of the Soil Mechanics Laboratory of Tabriz University, especially Prof. Masoud Hajialilue Bonab, for their assistance and support.

\section{REFERENCES}

AASHTO T99/T180 (15) Moisture-Density Relations of Soils. Washington, D.C.: American Association of State Highway and Transportation Officials.

ASTM Standard C192-C192M - 19 Standard Practice for Making and Curing Concrete Test Specimens in the Laboratory, ASTM International, West Conshohocken, PA, USA.

ASTM Standard C666-C666M - 15 Standard Test Method for Resistance of Concrete to Rapid Freezing and Thawing, ASTM International, West Conshohocken, PA, USA.

ASTM Standard E1621-13 Standard Guide for Elemental Analysis by Wavelength Dispersive X-Ray Fluorescence Spectrometry.

ASTM Standard D558-11 Standard Test Methods for Moisture-Density (Unit Weight) Relations of Soil-Cement Mixtures.

ASTM Standard D 1883-07 Standard Test Method for CBR (California Bearing Ratio) of Laboratory-Compacted Soils, ASTM International, West Conshohocken, PA, USA.

ASTM Standard D2419-14 Standard Test Method for Sand Equivalent Value of Soils and Fine Aggregate, ASTM International, West Conshohocken, PA, USA.

ASTM Standard D2487-17 Standard Practice for Classification of Soils for Engineering Purposes (Unified Soil Classification System), ASTM International, West Conshohocken, PA, USA.

ASTM Standard D5821-01 Method for Determining the Percentage of Fractured Particles in Coarse Aggregate, ASTM International, West Conshohocken, PA, USA.

Azzam, W. R. (2014). Behaviour of Modified Clay Microstructure Using Polymer Nanocomposites Technique. Alexandria Engineering Journal, 53(1), 143-150. https://doi.org/10.1016/j.aej.2013.11.010

Bandara, W. W., Mampearachchi W. K., \& Sampath K. H. S. M. (2017). Cement Stabilized Soil as a road Base Material for use in Sri Lankan Roads. The Institution of Engineers, Sri Lanka, 50(1), 21-29. https://doi.org/10.4038/engineer.v50i1.7241

Choudhary, R., Chattopadhyay, D., Kumar, A., \& Julaganti, A. (2017). Use of industrial wastes as filler in open-graded friction courses. The Baltic Journal of Road and Bridge Engineering, 12(2), 106-116.

https://doi.org/10.3846/bjrbe.2017.13
Influence

of "Nicoflok"

Polymer-Mineral

With Portland

Cement on Granular

Soils and Recycled

Asphalt Material 
Dejong, J., et al. (2013). Biogeochemical processes and geotechnical applications: Progress, opportunities and challenges. Géotechnique, 63(4), 287-301. https://doi.org/10.1680/geot.SIP13.P.017

Dołżycki, B., Jaczewski, M., \& Szydłowski, C. (2018). The Impact of Long-Time Chemical Bonds in Mineral-Cement-Emulsion Mixtures on Stiffness Modulus. The Baltic Journal of Road and Bridge Engineering, 13(2), 121-126. https://doi.org/10.7250/bjrbe.2018-13.406

Edil T. B. (2018). A Review of Recycled Aggregates (RAP and RCA) as Unbound Base Course Material for Sustainable Highway Construction. In: Tran-Nguyen HH., Wong H., Ragueneau F., Ha-Minh C. (eds) Proceedings of the 4th Congrès International de Géotechnique - Ouvrages -Structures. CIGOS 2017. Lecture Notes in Civil Engineering, vol 8. Springer, Singapore. https://doi.org/10.1007/978-981-10-6713-6_1

Gavrilina, I., \& Bondar, A. (2018). Analysis of Using Nicoflok Polymer-Mineral Additive for Replacing Stone Materials as Road Bases. IOP Conference Series: Materials Science and Engineering, vol. 451, 2018. https://doi.org/10.1088/1757-899X/451/1/012086

Gridchin, A. M., \& Zolotykh, S. N. (2018). PMC Nicoflok Research Effect as Mechanochemical Activator on the Cement Characteristic Used in the Soil Strengthen. Bulletin of BSTU, 3(5), 5-10. https://doi.org/10.12737/article_5af5a72640c9f7.36216170

Gusev, N. K., \& Nekhoroshkov, P. A. (2013). Study of Solidity of Road Structure Constructed with The Use of Polymer-Mineral Composition NMP. Bulletin of PSTU, 2013, 2, 52-58.

Han, J. (2015). Principles and Practices of Ground Improvement. John Wiley \& Sons, Inc., Hoboken, New Jersey, USA.

Joe, W., \& Button, P. E. (2003). Kiln Dust for Stabilization of Pavement Base and Subgrade Materials. Texas A\&M University System College Station, Texas, USA.

Kar, S. S., Swamy, A. K., Tiwari, D., \& Jain, P. K. (2018). Impact of Recycled Asphalt Pavement on Properties of Foamed Bituminous Mixtures. The Baltic Journal of Road and Bridge Engineering, 13(1), 14-22.

https://doi.org/10.3846/bjrbe.2018.383

Kirsch, K., \& Bell, A. (2013). Ground Improvement, Third Edition. CRC Press, Taylor \& Francis Group, USA.

Kolias, S., Kasselouri-Rigopoulou, V., \& Karahalios, A. (2005). Stabilisation of clayey soils with high calcium fly ash and cement. Cement and Concrete Composites. Cement and Concrete Composites, 27(2), 301-313.

https://doi.org/10.1016/j.cemconcomp.2004.02.019

Mishra, E. N. K. (2012). Strength Characteristics of Clayey Sub-Grade Soil Stabilized with Fly Ash and Lime for Road Works. Indian Geotech Journal, 42, 206-211. https://doi.org/10.1007/s40098-012-0015-5

Pereira, R., Emmert, F., Miguel, E., \& Gatto, A. (2018). Soil Stabilization with Lime for the Construction of Forest Roads. Floresta e Ambiente, 25(2), e20150077. http://dx.doi.org/10.1590/2179-8087.007715. 
Petry, T. M. \& Little, D. N. (2002). Review of stabilization of clays and expansive soils in pavements and lightly loaded structures- history, practice, and future. Journal of Materials in Civil Engineering, 14(6), 447-460. https://doi.org/10.1061/(ASCE)0899-1561(2002)14:6(447)

Rezaie Moghaddam, F., Jafari, N., \& Rezaie Moghaddam, T. (2020). Laboratory Investigation of the Effect of "NICOFLOK" Polymer on the Compressive and Tensile Strength of Desert and Coastal Sand at the pavement Layers. Amirkabir Journal Civil engineering, Articles in Press.

Sahu, V., Srivastava, A., Misra, A., \& Sharma, A. K. (2017). Stabilization of fly ash and lime sludge composites: Assessment of its performance as base course material. Archives of Civil and Mechanical Engineering, 17(3), 475-485. https://doi.org/10.1016/j.acme.2016.12.010

Schaefer, V. (2014). SHRP 2 Geotechnical Solutions for Soil Improvement, Rapid Embankment Construction, and Stabilization of the Pavement Working Platform. National Concrete Pavement Technology Center, USA.

Shojaei Baghini, M., Ismail, A., Naseralavi, S. S., \& Firoozi. A. A. (2016). Performance evaluation of road base stabilized with styrene-butadiene copolymer latex and Portland cement. The international Journal of pavement research and technology, 9(4), 321-336. https://doi.org/10.1016/j.ijprt.2016.08.006

Thakur, J. K., \& Han, J. (2015). Recent Development of Recycled Asphalt Pavement (RAP) Bases Treated for Roadway Applications. Transp. Infrastruct. Geotech. 2, 68-86. https://doi.org/10.1007/s40515-015-0018-7

Taha, R., Al-Harthy, A., Al-Shamsi, K., \& Al-Zubeidi, M. (2002). Cement Stabilization of Reclaimed Asphalt Pavement Aggregate for Road Bases and Subbases. Journal of Materials in Civil Engineering, 14(3), 239-245. https://doi.org/10.1061/(ASCE)0899-1561(2002)14:3(239)

Wang, S., Baaj, H., Zupko, S., \& Smith, T. (2018). Field and lab assessment for cement-stabilized subgrade in Chatham, Ontario. Conference of the Transportation Association of Canada, Saskatoon, SK, Canada.

\section{Appendix}

Table A. The CBR test results

\begin{tabular}{cccccc}
\hline Soil & $\begin{array}{c}\text { Curing, } \\
\text { days }\end{array}$ & Water, \% & NMP, \% & Cement, \% & CBR, \% \\
\hline Soil \#1 & 0 & 9.4 & 0 & 0 & 47.75 \\
\hline Soil \#1 & 1 & 9.4 & 0 & 1 & 78.09 \\
\hline Soil \#1 & 1 & 9.4 & 0.5 & 1 & 48.09 \\
\hline Soil \#1 & 1 & 9.4 & 0.9 & 1 & 60.95 \\
\hline Soil \#1 & 1 & 9.4 & 1.3 & 1 & 62.86 \\
\hline Soil \#1 & 3 & 9.4 & 0 & 1 & 95.13 \\
\hline Soil \#1 & 3 & 9.4 & 0.5 & 1 & 96.12 \\
\hline
\end{tabular}




\begin{tabular}{|c|c|c|c|c|c|}
\hline Soil \#1 & 3 & 9.4 & 0.9 & 1 & 101.09 \\
\hline Soil \#1 & 3 & 9.4 & 1.3 & 1 & 91.31 \\
\hline Soil \#2 & 0 & 15.2 & 0 & 0 & 5.52 \\
\hline Soil \#2 & 1 & 15.2 & 0 & 0.5 & 8.86 \\
\hline Soil \#2 & 1 & 15.2 & 0 & 1 & 24.39 \\
\hline Soil \#2 & 1 & 15.2 & 0 & 1.5 & 63.16 \\
\hline Soil \#2 & 1 & 15.2 & 0 & 2 & 115.67 \\
\hline Soil \#2 & 1 & 15.2 & 0 & 5 & 160.73 \\
\hline Soil \#2 & 1 & 15.2 & 0.5 & 1 & 21.41 \\
\hline Soil \#2 & 1 & 15.2 & 0.9 & 1 & 22.9 \\
\hline Soil \#2 & 1 & 15.2 & 1.3 & 1 & 23.23 \\
\hline Soil \#2 & 1 & 15.2 & 0.5 & 0.5 & 8.66 \\
\hline Soil \#2 & 1 & 15.2 & 0.9 & 0.5 & 15.44 \\
\hline Soil \#2 & 1 & 15.2 & 1.3 & 0.5 & 11.71 \\
\hline Soil \#2 & 3 & 15.2 & 0 & 1 & 71.44 \\
\hline Soil \#2 & 3 & 15.2 & 0.5 & 1 & 75.08 \\
\hline Soil \#2 & 3 & 15.2 & 0.9 & 1 & 81.38 \\
\hline Soil \#2 & 3 & 15.2 & 1.3 & 1 & 89.99 \\
\hline Soil \#3 & 0 & 9.8 & 0 & 0 & 35.66 \\
\hline Soil \#3 & 1 & 9.8 & 0 & 1 & 114.28 \\
\hline Soil \#3 & 1 & 9.8 & 0.5 & 1 & 91.43 \\
\hline Soil \#3 & 1 & 9.8 & 0.9 & 1 & 76.19 \\
\hline Soil \#3 & 1 & 9.8 & 1.3 & 1 & 82.86 \\
\hline Soil \#3 & 3 & 9.8 & 0 & 1 & 231.89 \\
\hline Soil \#3 & 3 & 9.8 & 0.5 & 1 & 223.69 \\
\hline Soil \#3 & 3 & 9.8 & 0.9 & 1 & 214 \\
\hline Soil \#3 & 3 & 9.8 & 1.3 & 1 & 211.75 \\
\hline Soil \#4 & 0 & 9.9 & 0 & 0 & 77.14 \\
\hline Soil \#4 & 3 & 9.9 & 0 & 1 & 233.39 \\
\hline Soil \#4 & 3 & 9.9 & 0.5 & 1 & 238.36 \\
\hline Soil \#4 & 3 & 9.9 & 0.9 & 1 & 246.8 \\
\hline Soil \#4 & 3 & 9.9 & 1.3 & 1 & 242.83 \\
\hline Soil \#5 & 0 & 5 & 0 & 0 & 10 \\
\hline Soil \#5 & 1 & 5 & 0 & 3 & 19.09 \\
\hline Soil \#5 & 1 & 5 & 0.5 & 3 & 25.24 \\
\hline Soil \#5 & 1 & 5 & 0.9 & 3 & 28.09 \\
\hline Soil \#5 & 1 & 5 & 1.3 & 3 & 20.42 \\
\hline
\end{tabular}




\begin{tabular}{cccccc}
\hline Soil \#5 & 3 & 5 & 0 & 3 & 40.79 \\
\hline Soil \#5 & 3 & 5 & 0.5 & 3 & 49.57 \\
\hline Soil \#5 & 3 & 5 & 0.9 & 3 & 50.9 \\
\hline Soil \#5 & 3 & 5 & 1.3 & 3 & 46.66 \\
\hline
\end{tabular}

Influence

of "Nicoflok"

Polymer-Mineral

With Portland

Cement on Granular

Soils and Recycled

Asphalt Material

Table B. After Freeze-thaw cycles CBR results

\begin{tabular}{ccccc}
\hline Soil & Water, \% & Cement, \% & NMP, \% & CBR, \% \\
\hline Soil \#5 & 5 & 3 & 0 & 34.99 \\
\hline Soil \#5 & 5 & 3 & 0.5 & 40.46 \\
\hline Soil \#5 & 5 & 3 & 0.9 & 58.68 \\
\hline Soil \#5 & 5 & 3 & 1.3 & 45.71 \\
\hline Soil \#4 & 9.9 & 1 & 0 & 167.04 \\
\hline Soil \#4 & 9.9 & 1 & 0.5 & 180 \\
\hline Soil \#4 & 9.9 & 1 & 0.9 & 194.28 \\
\hline Soil \#4 & 9.9 & 1 & 1.3 & 154.28 \\
\hline
\end{tabular}

